\title{
Shedding Light on the City: Discovering, Appreciating and Sharing Cultural Heritage using 3D Visual Technology
}

\author{
Elena Ippoliti, Annika Moscati \\ Department of history, design and restoration of architecture \\ La Sapienza, University of Rome \\ Rome, Italy \\ elena.ippoliti@uniroma1.it; annika.moscati@uniroma1.it
}

\author{
Alessandra Meschini, Daniele Rossi \\ School of Architecture and Design Edoardo Vittoria \\ University of Camerino \\ Ascoli, Italy \\ alessandra.meschini@unicam.it; daniele.rossi@unicam.it
}

\author{
Livio De Luca \\ UMR 3495 CNRS/MCC MAP-Gamsau \\ Marseille, France \\ livio.deluca@gamsau.archi.fr
}

\begin{abstract}
The present paper describes the initial results of the research "Integrated informative models to identify, appreciate and share urban and environmental heritage. Testing 3D interfaces for "cultural and geographic objects": architecture of information and computerized architecture". The main purpose of this research is to expand the concept of "integrated informative models" by studying integrations and overlaps from different environments, taking into consideration both geographical (3D GIS) and web (3D Web and 3D WebGIS) space as well as Virtual Reality (VR) and Augmented Reality (AR). The research aims at identifying technological, procedural and operational systems, structured specifically for each individual case, to define technology with easily accessible (cheap and/or open source) instruments characterized by reliable data processing. Within this framework, various experimentations have been carried out on the area we were privileged to work in, the historical centre of Ascoli Piceno, using different paths/measuring scales and following the necessary organization of data.
\end{abstract}

Keywords-3D WebGIS; Interactive environments; 3D modelling; Edutainment, Augmented Reality

\section{INTRODUCTION}

Any research assessing cultural heritage is based on at least two assumptions: the depth of understanding of each work of art and its location, and the proper communication of all the aspects of the acquired knowledge.

Use of new technologies for the documentation of cultural heritage has increased and consolidated and, as a result, the steps for assembling and communicating information have changed. At the same time there is a greater need for the organization of cultural content and how information should be properly communicated, with the aim of creating standard objectives and making sure that the methods used are reliable and technically accurate.
Within this framework, the present paper aims at highlighting the initial results of the research: "Integrated informative models to identify, appreciate and share urban and environmental heritage. Testing 3D interfaces for cultural and geographic objects: architecture of information and computerized architecture"1.

The starting point was identifying the numerous applications in the field of cultural heritage, also carried out under the scientific guidance of important institutions and centres of excellence, aimed at broadening the concept of "3D digital representation/models" into a "3D digital scene".

The 3D digital scene is meant to be a place for reflecting on cultural heritage as a whole, insomuch as it is an interface for accessing cultural content as well as a place where information is created. This interactive approach, based on sensory and emotional involvement, really gives additional value to communication and helps develop and process information and content. This makes it an extremely useful tool for the appreciation of our cultural heritage.

Based on these observations, the main purpose of our research has been to expand the concept of "integrated informative models" by studying integrations and overlaps from different environments, taking into consideration both geographical (3D GIS) and web (3D Web and 3D WebGIS) space as well as Virtual Reality (VR) and Augmented Reality (AR).

Our aim was also to identify technological, procedural and operational systems, structured specifically for each individual case, to define technology with easily accessible (cheap and/or open source) instruments characterized by reliable data processing.

\footnotetext{
${ }^{1}$ Within the inter-university research program on the national interest PRIN "Complex Models for the urban-architectural heritage ", co-funded by MIUR (PRIN 2008), scientific coordinator prof. Mario Centofanti, local unit composed by Elena Ippoliti, manager, Alessandra Meschini, Daniele Rossi, with Annika Moscati and Livio De Luca, 2010-2012.
} 
The purpose of these systems is to experiment with different combinations of levels and qualities of complex knowledge. Three-dimensional models will be set up in relation to actual space, geographical space (3D-GIS) and WEB space, to create the ultimate means of transmitting and diffusing information on cultural heritage.

The research is being developed along the lines of three important goals that merge together to create one general fundamental objective which we describe in detail at the different stages.

From the point of view of the method we chose to follow, we describe different situations which had to be addressed, by describing the different application fields (which are specific to different problem areas and can be used as standard, repeatable, serial models with characteristics that make them easy to sort into groups), with the definition of the protocols followed, together with projects for creating different data models.

From a scientific-technological point of view the main goal was to find three main procedural protocols:

- incorporating 3D information levels with GIS, and incorporating 3D-GIS with WEB;

- overlaying different multimedia information levels with reality (Augmented Reality);

- introducing elements, objects, real people into a virtual space, or rather the definition of interactive levels with the participation of a real subject in a virtual world (Augmented Virtuality).

From an operational point of view, we aimed at running experimentations on the main study cases to test, evaluate and eventually to refine the previously-defined procedural and operative protocols, once having identified useful channels to promote and divulge the results and which could possibly lead us to find other areas to usefully apply this know-how.

The area we chose to work with is the historic centre of Ascoli Piceno, starting from its main squares: Popolo Square and Arringo Square.

Within this framework, our research moved towards various directions and applications, dealing with the following different paths/measuring scales and with the resulting organization of data:

- 3D WebGIS between an urban/architectural scale: Popolo Square. Testing a cognitive process which makes it possible to go from a 3D WebGIS urban scale to a 3D WebGIS architectural scale by connecting two different databases, and by creating a new interface for access to information.

- New urban representations: Arringo Square. Experimentation with 3D reconstructions of the space (synchronous and asynchronous) in its current state and in other particular periods of history chosen according to the best maps available.

- Live urban scenography. Simulation of architectural video projections, on the facades of churches and buildings in Ascoli Piceno.
- Virtualization for the appreciation of museum itineraries: the National Archaeological Museum of Panichi Palace. Experimentation using VR and AR applications to evaluate museum contents to define fast and effective ways for capturing, processing and handling the metric and geometric data of cultural objects.

\section{3D WebGiS between an Urban/Architectural Scale: Popolo Square}

The main purpose of this part of the research was to pass from a 3D web GIS to an urban scale and then to an architectural scale by blending two systems: Geographic Information Systems (GIS) that manage urban-territorial scale data, and Architecture of Information Systems (AIS) that deal with an architectural scale by breaking down three-dimensional models ${ }^{2}$.

In the first case, we re-edited the free and open source p.mapper with MapServer; and in the second case we used the Nubes platform, developed by the researchers at the UMR 3495 CNRS/MCC MAP-Gamsau laboratory in Marseille. Nubes is a platform that makes it possible to carry out projects with different viewpoints, with which we can create entities, that is vector points in 3D space, which we can describe as a series of data such as 3D models.

With this in-depth study of the two systems, we came to the conclusion that the most interesting characteristic of GIS is its capacity to analyse space as it depicts the topology of the inserted vector elements. If topological analysis is GIS's strong point, then its extension to a three-dimensional level is the most likely road to achieve a true 3D GIS.

The goal of merging the two systems was fulfilled by creating a new interface, accessible from the Web, with which it is possible to see, manage and research in $2 \mathrm{D}$ and $3 \mathrm{D}$ at the same time. The structure of the two systems was left untouched; as a matter of fact we took advantage of working in parallel with the two independent databases.

The new interface has a graphic structure (Fig. 1), which is split into three: a window to visualize Nubes, one to see and manage the WebGIS and one for the query editor ${ }^{3}$.

What connects the two databases is the square (piazza) itself because it is both an urban and an architectural element. The square, based on a scale system, is defined by the buildings that surround it.

\footnotetext{
2 This part of the research was developed in particular by Annika Moscati within the framework of a PhD thesis entitled "Integrated informative systems to evaluate urban-architectural heritages, using 3D GIS, AIS and Web”, tutor professor Elena Ippoliti, co-tutor Livio De Luca, PhD in Representation and Survey, Department of Architectural History, Design and Restoration, La Sapienza University, Rome. Part of experimentation carried out at the UMR 3495 CNRS/MCC MAP-Gamsau Laboratory in Marseilles, directed by Livio De Luca.

${ }^{3}$ It's easily accessible from the web page http://brunelleschi.gamsau.archi.fr/ index.php.
} 


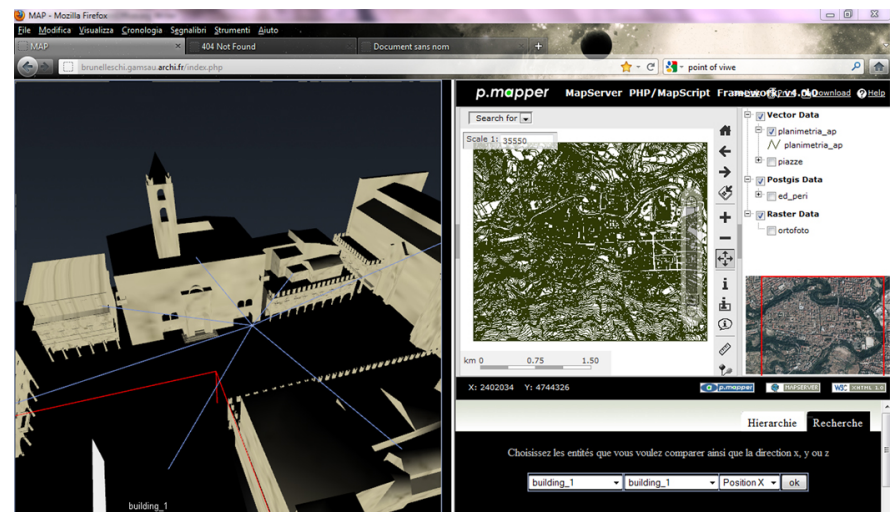

Fig. 1. 3D WebGIS between an urban/architectural scale: hybrid interface

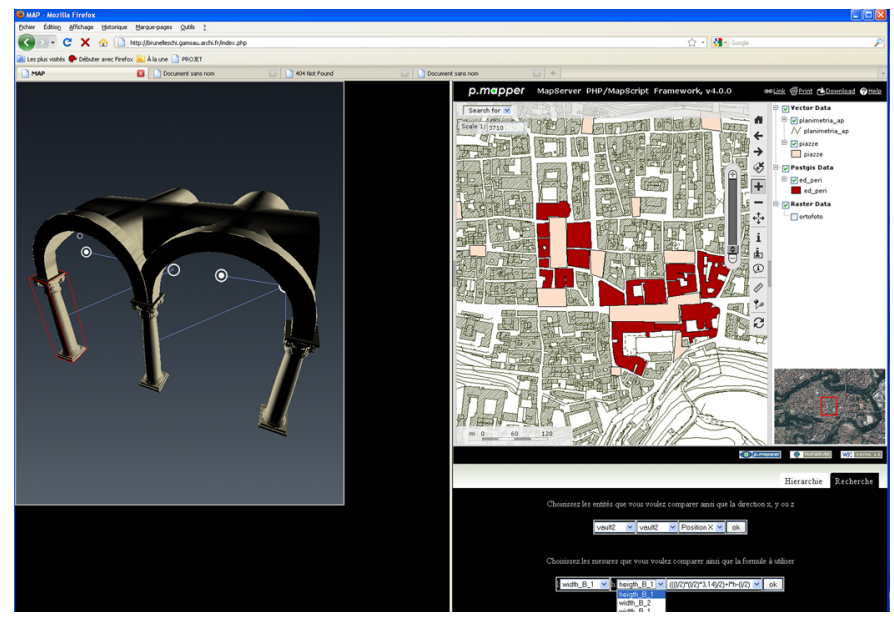

Fig. 2. 3D WebGIS between an urban/architectural scale: query interface

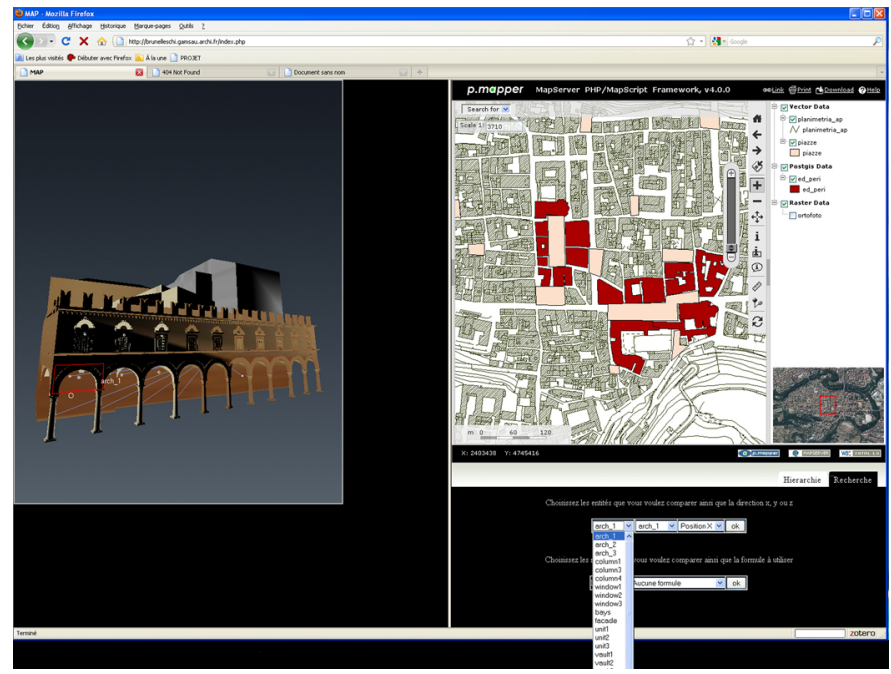

Fig. 3. 3D WebGIS between an urban/architectural scale: query interface

A building, the only entity which is in both systems, is the smallest object you can search for in the WebGIS and the largest in the AIS, which is why it was chosen as the link between the two. The connection took place by associating the unique codes of each database with a php script.

We then studied the topological queries to create possible 3D models and experimented the ones which it was feasible to scripture using the characteristics of the database and the systems employed. Thanks to the query editor in the new interface it is possible to study the models, based on the alignment of the single architectural elements, in the three directions (X, Y, Z) or also based on the relative scale and dimensional comparison of the various bays (Figs. 2-3).

There are two themes that have influenced (and limited) our research: the characteristics of the place we chose to study and the difficulty of applying topological connections to a 3D space.

We chose Popolo Square in Ascoli Piceno because it satisfied a series of requirements the thesis had; for example, it allowed us to work in a space which was both urban and architectural, to have different building types, ranging from the urban weave to prominent elements, as well as having repetitive features which we can almost consider as serial (columns, arches, bays, etc.). The space we chose inevitably influenced the creation of the database, which centred around the description of the square, and the choice of spatial analysis, because we used whatever was most relevant to this square.

We hypothesized that the creation of an efficient 3D GIS system depends on its capacity to script topologies in 3D space. In this way the 3D models, which can already be imported into systems today, don't only represent the elevation of the buildings, but become proper interfaces to access information and efficient tools for research.

There are several difficulties and limits with 3D topology, such as having the capacity to imagine useful queries for 3D analysis and, above all, the impossibility of comparing the work to standard models or to other completed studies.

\section{New Urban Representations: Arringo Square}

The main objective of our research was to find new ways of transmitting cultural information regarding urban space, particularly historically relevant places, which could underline the multi directional and dynamic aspects of the city according to the individual works of art which represent it.

We are convinced that an exploration based on perception is an effective way of communicating built-up space. With this in mind we aimed at producing a new way of illustrating the city which would communicate knowledge creatively, using technology to stimulate visual senses and communication.

Starting from this objective, we experimented with applications that are able to expand the concept of " $3 \mathrm{D}$ digital model" into "3D digital scene", with regard to a particular aspect of cultural (urban and architectural) heritage. This is done by improving the effectiveness of communication and information using specific 3D interface arrangements that encourage perceptive exploration and thus make the content easier to understand.

The place we effectively used these applications on is Arringo Square, one of the two main squares in the centre of Ascoli Piceno. The perfect place to embody the city also thanks to the important roles of the "empty" and the "full" spaces that are the main features of its urban form. The square is a prolonged rectangle; on its long side it follows the ancient Salaria road which passes through the city centre. Some of the "full" spaces that delimit the square are important architectural buildings such as: Arringo Palace, Bishop’s Palace, St. Emidio 
Cathedral, Baptistery of St. Giovanni and other historical buildings.

What connects all these elements is history. As a matter of fact, the fundamental purpose of experimenting with these applications was to create a 3D chronicle of the square that sums up the main transformations which occurred between the XIII century and the present ${ }^{4}$.

The first step of the procedure we followed was to rebuild the square in 3D, in its actual state. The urban system and the single architectural elements are not reproduced in great detail.

With the purpose of describing the metric-geometric configuration and the qualities of the space and the materials the objects are made of, we chose to use a photo-modelling technique. That is, an instrument that is easy to use, with cheap software, but still reliable regards quality of the data (metric, geometric and surface). Processing the details of space (width and number of buildings that create it) was complex because of the quantity of photographs needed and because of the number of models that had to be created (Fig. 4).

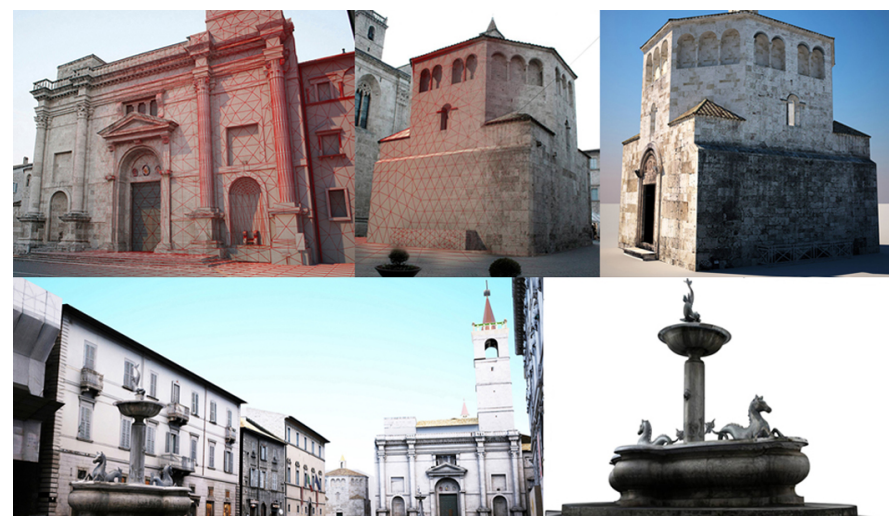

Fig. 4. Building a 3D model of the existing condition: photo modelling. The Cathedral, the Baptistery, Arringo Square (as a whole) and fountains

Based on the actual size and shape of the square, we then created 3D constructions of it at certain points in history. We started with the best maps (the pseudo-perspective representation of Emidio Ferretti in 1646, the Gregorian Registry in 1819 and the Dicastero Papers from the census of 1845) and the many bibliographic references in documents and archives, in particular iconographic and photographic ones. Thanks to all these documents testifying its development, it was possible to use the photo modelling technique.

In the end, starting from the models we began overlapping different multimedia information levels, taking into consideration different ways of organizing cultural data, always with the aim of describing the urban space as a whole. To be more precise we determined the levels of interaction, with the participation of the virtual environment, using synchronous and asynchronous panoptical Virtual-Tour applications and stereoscopic vision.

Panoptical Virtual-Tour applications make you feel a part of the experience thanks to the $360^{\circ}$ perception view through a fixed monitor (which can be either in online or offline mode).

\footnotetext{
${ }^{4}$ This part of the research was carried out with the enthusiastic and competent collaboration of Jonathan Sileoni and Danilo Spinozzi, Master's graduates, School of Architecture and Design, University of Camerino, Ascoli Piceno, Italy.
}

It is interactive because the user can choose the historical period personally and make changes (zooming in or out, rotating possible views), thus creating a system which pays attention to possible movement simulations in space. A time slider allows the user to choose and handle the different historical moments. Also, the predisposition of areas sensitive to different types of information (alphanumeric and iconographic) for each building, enhances the interactive aspect. The different 3D-panoptical scenes can be appreciated by looking at each individual building that creates the scene. In this way, they are organisers of precise information about themselves and represent 3D access interfaces (Fig. 5).

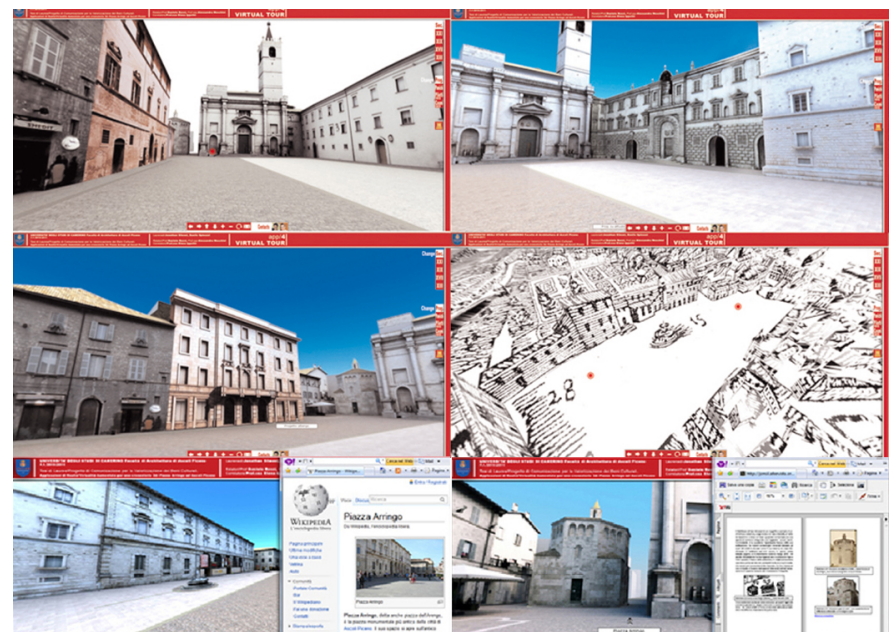

Fig. 5. 360-Virtual tour view applications: reconstruction from the existing condition to that of the XIII century, possible links to catalogued information

The application that was able to produce a series of stereoscopic visions of the actual 3D reconstruction, which can be tested using a pair of anaglyph glasses, was created by pairing images together using the 3D Studio Max rendering command. They were then assembled properly to achieve stereoscopic vision by using well-known commercial graphic software, both at a cost (Adobe) and free (GIMP).

With these technical applications the goal was to widen the depth perception of the 3D scenes, or rather the three dimensionality of the space in the square. As a matter of fact this system creates an "augmented" virtual experience, where we can describe the level of interaction as a visual immersion, able to get the user emotionally involved with a strong impact of the spatial qualities of the square (Fig. 6).

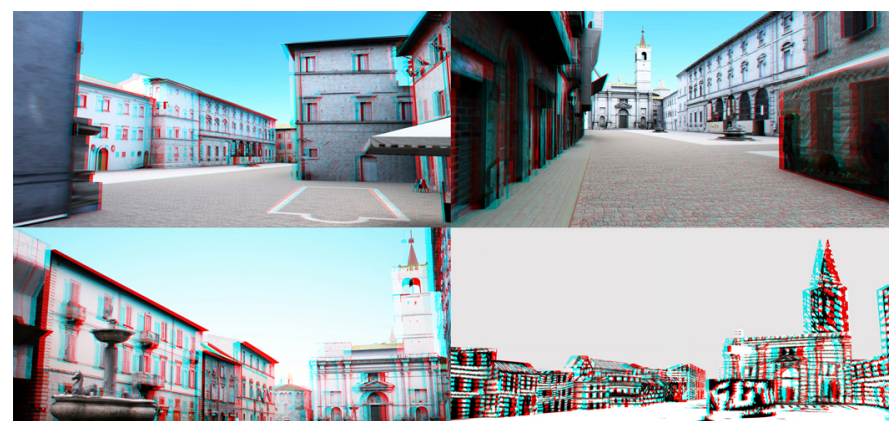

Fig. 6. Stereoscopic applications: past and present views of Arringo Square 
IV. Live Urban Scenography. Simulation of Architectural Video Projections, on the Facades of Churches and Buildings in Ascoli Piceno

Usually one talks about Augmented Reality when describing a flow of video images, captured in real-time by a television camera, or by a webcam; "Augmented” because of the presence of digital content. Nowadays the concept is much broader and the number of applications is so high and variable that it is difficult to set up.

The most recent studies with digital technologies have produced an even closer, detailed and profitable blending of what is real and what is virtual, grouping the applications that can be used into one category called "Augmented Reality". The levels of multimedia information superimpose themselves on real experience: the subject who is living the experience moves in a space which is ever-expanding thanks to the overlapping of more and more graphic or text information.

An augmented reality system is therefore created with a combination of the true scene the user is seeing with a digital, virtual event or a series of contents that enrich perception. Creating an experience, without using visual devices, thanks to video projection, for example, onto large architectural surfaces, means creating a virtual representation in a real space.

The process of creating a scenographic video projection is made possible by carrying out a precise, two-dimensional mapping of the surface to project onto; this mapping represents the mask that can filter the video content, creating a result that is perfectly in line with the real volume. Practically what we do is "acquire" the projection surface so as to create an exact image of it which is then re-projected onto the surface itself.

To verify that this type of product is possible, we tested it with applications on real models to scale.

Before choosing the case studies, we had to determine the most useful urban area which had each type of cultural object we wanted to project onto (the centre of Ascoli Piceno). In this urban context we then identified the single facades of churches and buildings on which to project and with which to experiment. Once we had identified these case studies we then defined a scientific-technological reference for the tools and procedure protocols that were consistent with the specific requirements of the documentation and the knowledge of cultural heritage.

The hardware and software technologies involved in this type of installation can be varied but focus around resolving three main points.

The first involves having thorough knowledge of the surface on which to project. As mentioned before, it is fundamental to know the geometry on which we are going to project, so as to be able to trace a $2 \mathrm{D}$ reference mask which will then be used to compile the video. Even if surveys, photoplans or 3D scans are available, it is best to verify in the actual area, through a sort of trial, according to the exact position of the projectors, how the ray of projected light will frame the building and therefore cast the mask over the surface.

In the experimentations carried out, this phase was made easier thanks to the fact that the scaled models of the facades were built based on the surveys themselves. Nonetheless an accurate check-up of the mapping was necessary, especially in those cases where there were large overhangs such as balconies or tympanums or other sculptural elements that could create shadow zones on the walls we wanted to project on.

The second problem was about processing the audio/video contents corresponding to the area in which and on which we projected. The main issue being to define the information level we wanted to achieve with regard to the architectural construction.

Architectural video projections, being so ephemeral, forced us to concentrate, in a limited time-frame (usually 10-15 minutes), a series of content mainly aimed at pure entertainment, with frequent use of special effects (fragmentations, explosions, simulation using digital figures and clothing or particle systems), but also designed for an understanding of spatial intelligence and of the historical evolution of the construction.

Specifically, the two types of buildings we chose churches and large buildings - allowed us to approach the project in two different ways, based on the architectural partitioning of the facades. The churches, most of which are Romanesque, were characterised by a wide surface of travertine marble, geometrically surrounded by one or more wooden portals, pilasters or columns attached to the walls, as well as cornices and rose windows. The large buildings, on the other hand, were characterised by a wide surface marked by a sequence, more or less orderly, of windows, portals and a series of architectural traces covered up by the numerous alterations carried out over time.

The third issue was about the positioning and calibration of the projection systems. This is a problem which is specific to this type of fitting, and which depends totally on the technological equipment available, that is on the managers, media servers and digital projectors that go to make up the hardware for architectural video-installation.

The audio/video signal is managed by the computer. The media server receives the video signal and has to deal with warping (that means the anamorphic correction of the video signal based on the projection surface), edge blending (that is the pairing up of the different video signals in the event of a surface that is so big it needs a series of projectors) and the timeline, where a sequence of clips gets put together to create the final animation. 


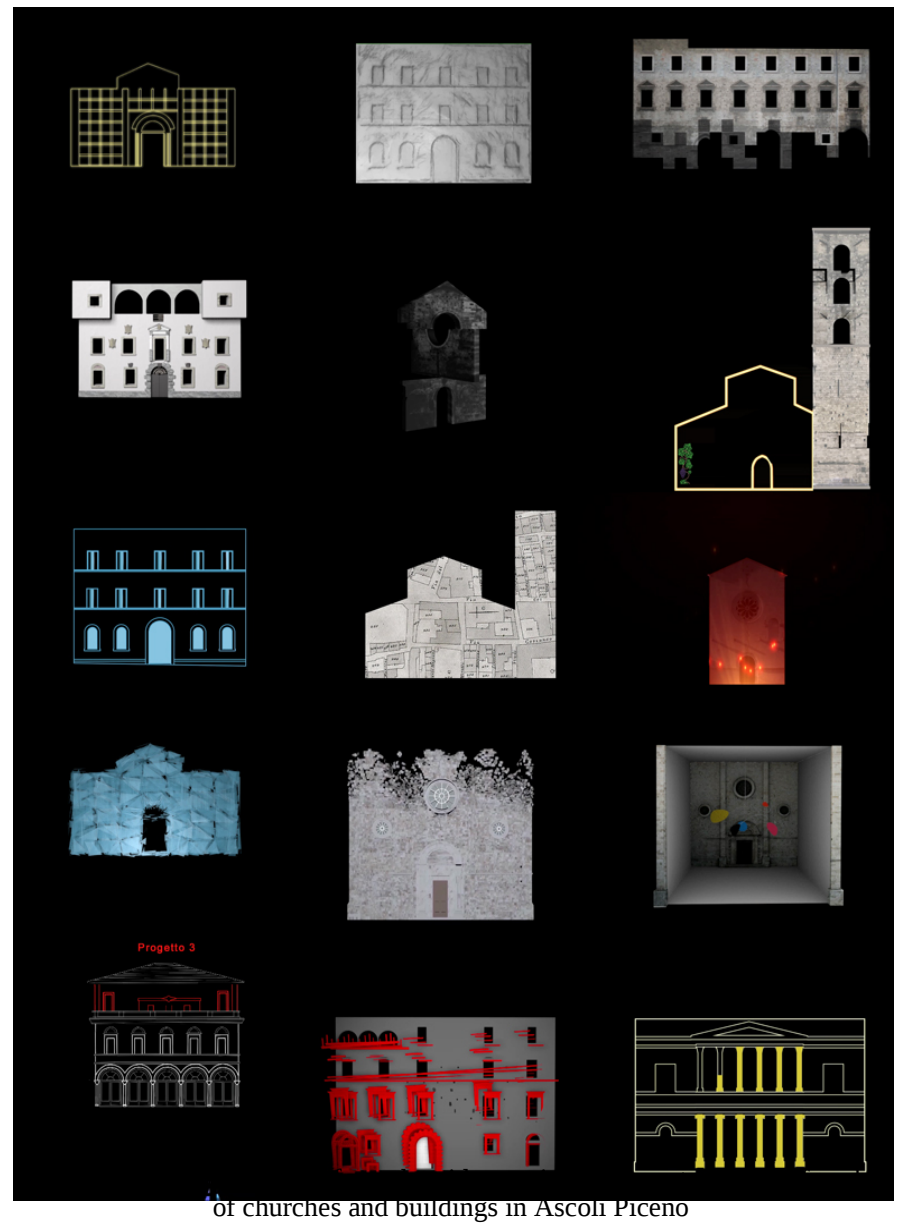

Lastly there are the digital projectors, which are high performance video projectors (about 30k lumen), that need to be installed in just the right place according to the reference mask mapped out in the first phase when analysing the projection surface.

The experimentations were conducted in a laboratory on models using a scale of 1:50. This allowed us to simplify what technological hardware was to be used, reducing it to just a personal computer, to manage the video flow with 1280x1024 pixel resolution in a QuickTime format video, and an inside benQ projector, model MP770 of 3200AnsiLumen, connected via a VGA cable and positioned $2.5 \mathrm{~m}$ from the wall where the models to be projected on were positioned.

This research has allowed us to examine and test out the projection of certain embellishments to scale, created according to specifically-traced masks and facade surveys. In this way, we have been able to test new approaches in the field through the use of different visual effects, approaches that imply basing visual exploration mainly on perceptual and emotional criterion. The result is a collection of micro-representations with an average running time of about 5 minutes.

These projections, aimed at both educating and entertaining, manage to present historical/architectural information, based both on the single architectural construction as well as the urban space where the construction is found, in an expressive form (Figs. 7-8).

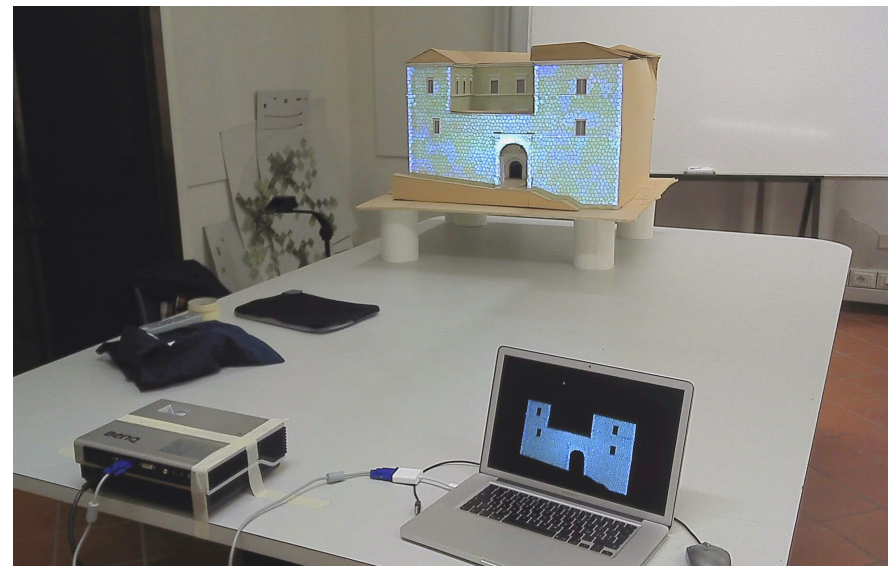

Fig. 8. Setting up an architectural video projection system in the laboratory

V. Virtualization for the Appreciation of Museum Itineraries: the National Archaeological Museum of Panichi PALACE

Our studies suggest the possibility of introducing new functions to communicate the content of museums. We started by re-thinking the meaning of a museum; making it become a place where, thanks to technologies that are based on communicating and interacting with displays and contents, the user becomes the main character of the experience.

Keeping in mind the different characteristics of possible visitors, we realized it was important to keep the relationship between familiarity and 'easy to use' stable. We achieved this thanks to technological interfaces that support visual senses and through which it is possible to access information and/or activate functions.

This experience aimed to find technologies and applications that could stimulate the desire to make the most of our cultural heritage, through museums and, in this way, expanding cultural education.

By involving and collaborating with the Director of the Museum $^{5}$, we decided to create such an experience in the National Archaeological Museum of Ascoli Piceno, which is situated in the Ridolfi-Panichi Palace on the north side of Arringo Square. The historical relevance of this building, and of how it overlooks such an important urban space, made us reconsider our methods: we wanted to experiment a new project that would emphasize the museum on different scales. That is we wanted to look at it from a construction-urban point of view which considers the "container", that is the building itself, as well as the objects that are found inside. Effectively this helped us to pinpoint our range of possible applications to be simulated and experimented ${ }^{6}$.

\footnotetext{
${ }^{5}$ Dr. Nora Lucentini, Archaeologist, General Management of Antiquities Superintendence for Archaeological Patrimony, Marche, Italy.

${ }^{6}$ This part of the research was carried out with the enthusiastic and competent collaboration of Catia Silvestrini and Giulia Poeta, Master's graduates, School of Architecture and Design, University of Camerino, Ascoli Piceno, Italy.
} 

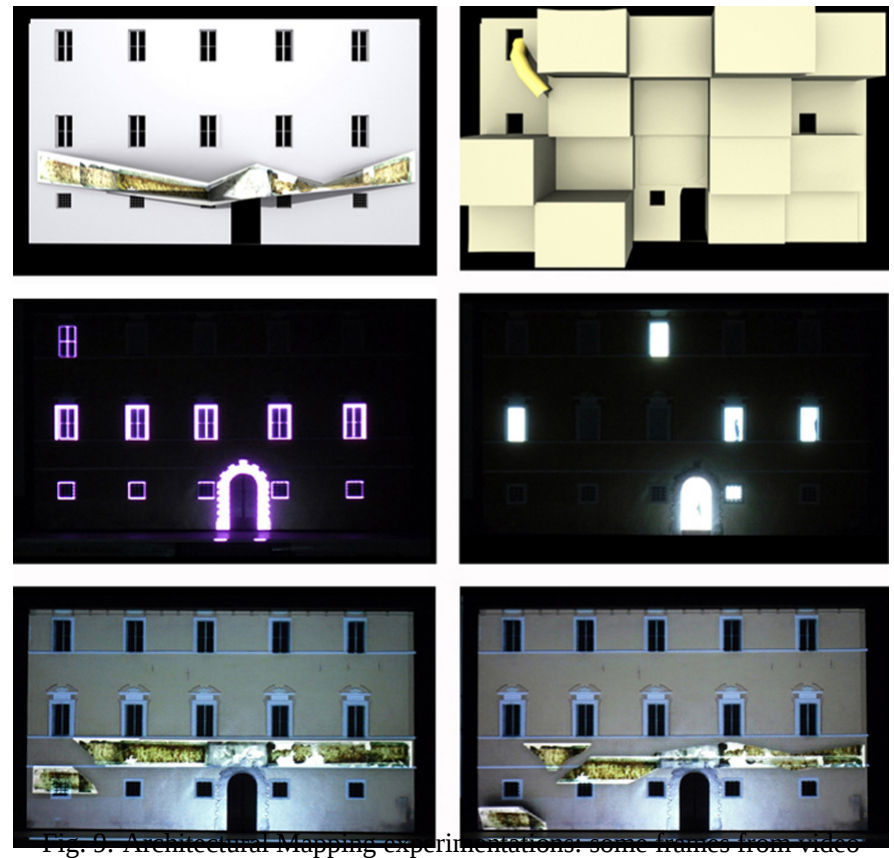

projections made for the facade of the Panichi Palace

With regard to the urban scale of the building, the experimentation mostly dealt with laboratory simulations of Architectural Mapping applications. This is a technological media system that creates a perceptual experience of the urban context, where the user basically looks at a representation that conveys a highly emotional impact.

Using 3D video contents we can "map" architecture, by inserting shapes that emphasize the elements and geometric characteristics of the surface. Through an animation project that included elements from the front of the building, the 3D projections made it possible to create a visual relocation of the frieze which was characteristic of the Panichi Palace building until 1971; as a matter of fact after this date the frieze was removed because of its poor condition, to conserve it, leaving the building bare (Fig. 9).

On the other hand, with the contents scale of the museum we decided to experiment with Augmented Reality, again from a visual point of view. We found interactive graphic systems based on application software that were either cheap or free, and that had specific rendering and tracement devices permitting us to apply virtual elements to real scenes. These applications calculate the interactivity with the user, and aim to modify and broaden the ways the visitor receives information about certain museum exhibits, enabling them to "live" a new experience based on a recreational approach and active involvement.
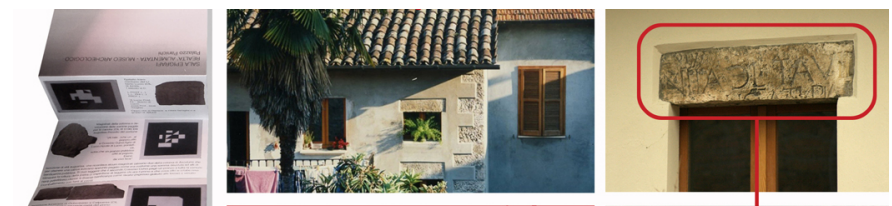

6
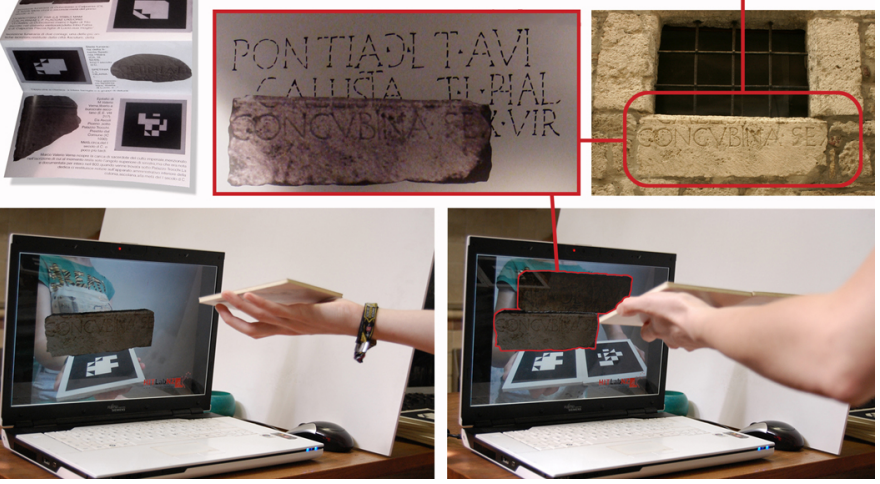

Fig. 10. Augmented Reality desktop applications: the sepulchral Epigraph of the concubine Pontia Callista

After an in-depth review of the Museum's contents, we identified which exhibits were to undergo our "desktop" RA experimentation applications. We decided it was going to be the Epigraph Collection which was displayed in the rooms of the Romanesque Lapidary. We decided to work on their 3D digital reconstruction by using photo modelling. A specific application was used for the sepulchral epigraph of the concubine Pontia Callista. This piece, from an unidentified period in history, had been divided into two and reused in a private construction in the city centre (in Rua Carlo Palucci, 1): part of it as a window pane on the east side of the building and the other as a window architrave on the north facing side of the building. Using photographs of the visible parts, it was possible to rebuild a 3D model of the epigraph thanks to photo modelling techniques. RA applications allowed us to create a particular integration of this piece into the collection, making it visible, at least virtually, to the public (Fig. 10).

In general, using 3D PDF formats, we presumed that all the 3D models created could be used and added in the museum catalogue to amplify it, linking them to an alphanumeric consultation, and making it easier to explore the virtual models, not only circling around them but also understanding simple measurements.

The idea of AR used on mobile devices has only been simulated until now, creating applications for specific exhibit pieces (a base, a few stone blocks and a capital) that were once part of an ionic column. These pieces are now shown on a scaffold that divides them vertically. In this specific case, obviously putting a notice with an explanation next to the exhibit, the application would allow us to apply a 3D projection adding the missing pieces to the real pieces showing what the column used to be like as a whole (Fig. 11). 

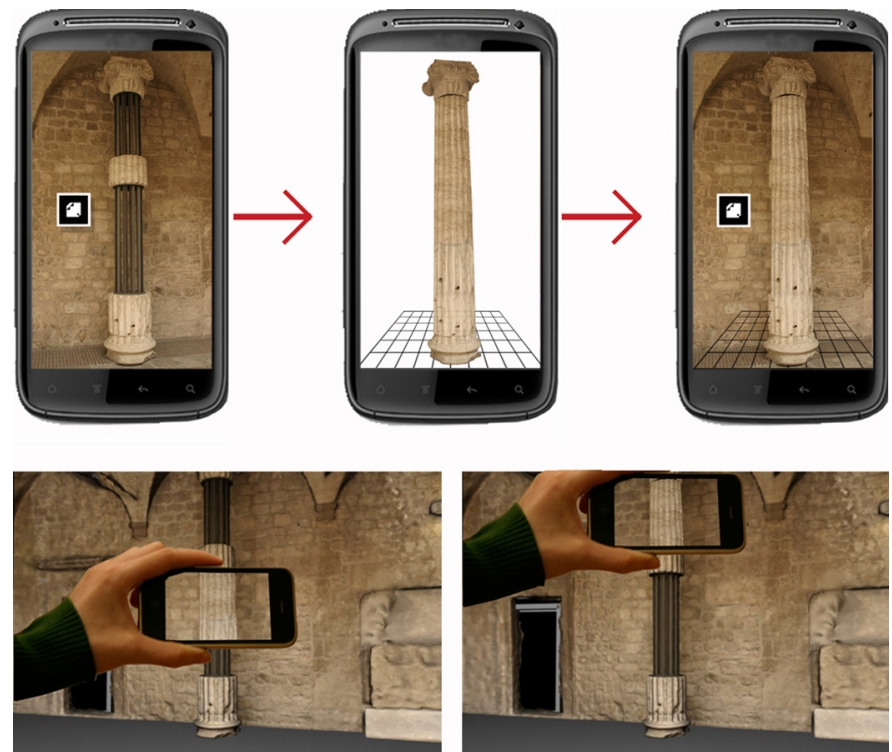

Fig. 11. Augmented Reality experimentations for mobile devices: simulations of a virtual reconstruction of the ionic column

\section{Conclusions}

One of the objectives of the presented research was to extend the concept of "integrated information model" through some special applications that are usual in the archaeological field, instead rare and not systematic in the architectural-urban one.

Although the research is still in progress, the initial results obtained allow to highlight some general considerations. First, the numerous experiments made it possible to verify how these new forms of representation, based on three-dimensional space (real and virtual), are useful because they allow to amplify the dimension and the communicative efficiency of cultural content. In this sense it is believed that these early examples, even in their originality, help to define a framework of typical fields of application and therefore are generalizable, i.e. repeatable.

In addition, some of the examples have shown how these applications can be easily realizable thanks to the reduced financial commitment and to the ease of use. The reliability of data quality and the ability to attract a growing number of public toward the cultural heritage knowledge, show that these applications may be considered particularly effective for the enhancement of cultural heritage, also in urban areas.

\section{REFERENCES}

[1] F. Antinucci, Parola e immagine: storia di due tecnologie, Laterza, Roma-Bari, 2011.

[2] L. De Luca, C. Busarayat, C. Stefani, P. Véron, M. Florenzano, “A semantic-based platform for the digital analysis of architectural heritage”, in Computers \& Graphics, v. 35, Issue 2, April 2011, pp. 227-241. http://www.sciencedirect.com/science/article/pii/S0097849310001780.

[3] E. Ippoliti, A. Meschini, edit by, "Tecnologie per la comunicazione del patrimonio culturale", in Disegnarecon, vol. 4, n. 8/2011, pp. 1-138, ISSN 1828-5961, http://disegnarecon.cib.unibo.it/index.

[4] F. Cervellini, D. Rossi, “Comunicare emozionando. L'edutainment per la comunicazione intorno al patrimonio culturale”, in Disegnarecon, edit by E. Ippoliti, A. Meschini, vol. 4, n. 8/2011, cit., pp. 48-55, ISSN 18285961, http://disegnarecon.unibo.it/article/view/2568.

[5] E. Ippoliti, "Media digitali per il godimento dei beni culturali”, in Disegnarecon, edit by E. Ippoliti, A. Meschini, vol. 4, n. 8/2011, cit., pp. 2-13, ISSN 1828-5961, http://disegnarecon.unibo.it/article/view/2564.

[6] A. Meschini, "Tecnologie digitali e comunicazione dei beni culturali. Stato dell'arte e prospettive di sviluppo”, in Disegnarecon, edit by E. Ippoliti, A. Meschini, vol. 4, n. 8/2011, cit., pp. 14-24, ISSN 1828-5961, http://disegnarecon.unibo.it/article/view/2565.

[7] E. Ippoliti, D. Rossi, A. Meschini, A. Moscati, “An approach towards the construction of a digital atlas for the documentation of cloisters and courtyards in Ascoli Piceno", in 3D Virtual Reconstruction and Visualization of Complex Architectures, edit by F. Remondino, S. ElHakim, Proceedings of the 4th ISPRS International Workshop 3DARCH 201, Trento, 2011, pp. 1-8. ISSN 16821777.

[8] E. Ippoliti, A. Meschini, "La "scena 3D" per la valorizzazione del patrimonio culturale architettonico e urbano: piazza Arringo ad Ascoli Piceno", in S.A.V.E. Heritage - Safeguard of Architectural, Visual, Environmental Heritage, edit by C. Gambardella, Proceedings of the IX Internazional Forum Le vie dei Mercanti, La scuola di Pitagora, Napoli, 2011, pp. 1-10. ISBN 978-88-6542-046-1.

[9] A. Moscati, J. Lombardo, L. Valentino Losciale, L. De Luca, "Visual browsing of semantic descriptions of heritage buildings morphology", Proceedings of DMACH 2011, Digital Media and its Applications in Cultural Heritage, Amman, Jordan, 13-15 March 2011.

[10] E. Ippoliti, A. Meschini, "Dal "modello 3D" alla "scena 3D". Prospettive e opportunità per la valorizzazione del patrimonio culturale architettonico e urbano", in Disegnarecon, edit by C. Bartolomei, La documentazione dei beni culturali, vol. 3, n. 6/2010, pp. 77-91, ISSN 1828-5961, http://disegnarecon.cib.unibo.it/article/view/2083.

[11] E. Ippoliti, "Mappe, modelli e tecnologie innovative per conoscere, valorizzare e condividere il patrimonio urbano. Indagini sperimentali di sistemi integrati sul Piceno", in Sistemi informativi integrati per la tutela la conservazione e la valorizzazione del patrimonio architettonico e urbano, edit by S. Brusaporci. Gangemi, Roma, 2010, pp. 240-251. ISBN 978-88-492-1860-2.

[12] E. Ippoliti, A. Moscati, "Interfacce di accesso alle informazioni: tra 3D, 3D-GIS e Web Gis”, in Sistemi informativi, op. cit., 2010, pp. 310-319.

[13] A. Meschini, "La progettazione del modello dei dati: tra standard e caso studio”, in Sistemi informativi, cit., 2010, pp. 271-283.

[14] A. Moscati, “Architettura delle informazioni: il database”, in Sistemi informativi, cit., 2010, pp. 284-291.

[15] D. Rossi, "Rappresentare le informazioni: interpretare, visualizzare, pubblicare dati geografici”, in Sistemi informativi, cit., 2010, pp. 252259.

[16] A. Granelli, M. Scanu, edit by, (Re)design del territorio. Design e nuove tecnologie per lo sviluppo economico dei beni culturali, Fondazione Valore Italia, Roma, 2009. ISBN 978-88-95540-04-7.

[17] V. Giardino, M. Piazza, Senza Parole. Ragionare con le immagini. Bompiani, Milano, 2008. ISBN 978-88-452-6162-6.

[18] M. Cusanno, D. Rossi, A. Rossi Brunori, "L'officina degli strumenti a codice aperto", in Disegnarecon, edit by R. Mingucci, M. Centofanti, Conservazione del Patrimonio Architettonico e Urbano, vol. 1, n. 2/2008, pp. 1-9, ISSN 1828-5961 http://disegnarecon.cib.unibo.it/article/view/1376.

[19] E. Ippoliti, A. Meschini, A. Moscati, “Architettura delle informazioni e architettura informatica. Sul caso studio di Appignano del Tronto”. in Disegnarecon, edit by R. Mingucci, M. Centofanti, Conservazione del Patrimonio Architettonico e Urbano, vol. 1, n. 2/2008, pp. 1-10, ISSN 1828-5961, http://disegnarecon.cib.unibo.it/article/view/1375.

[20] L. Manovich, Il linguaggio dei nuovi media. Olivares, Milano, 2008. ISBN 88-85982-61-1.

[21] F. Antinucci, Comunicare nel museo, Laterza, Roma-Bari, 2004.

[22] P. A. Valentino, L. M. R. Delli Quadri, edit by, Cultura in gioco: le nuove frontiere di musei, didattica e industria culturale nell'era dell'interattività, Giunti, Firenze, 2004. 